\title{
Three-dimensional simulations of strong ground motion in the Sichuan basin during the Wenchuan earthquake
}

\author{
Yanyan Yu ${ }^{1} \cdot$ Haiping Ding ${ }^{1} \cdot$ Qifang Liu ${ }^{2}$
}

Received: 12 December 2016/Accepted: 9 May 2017/Published online: 18 May 2017

(C) The Author(s) 2017. This article is an open access publication

\begin{abstract}
A three-dimensional model of the Sichuan basin was established by incorporating the Quaternary Chengdu plain, the near surface sediment, the crystalline basement, the $1 \mathrm{D}$ crustal velocity structure, and the realistic surface topography of the basin. Based on this model, and by using the spectral-element method and a parallel computing technique, the low frequency $(0.05-0.5 \mathrm{~Hz})$ wave amplification behavior of the Sichuan basin during the 2008 Wenchuan earthquake was simulated, and the frequency-related amplification characteristics were investigated. The results reveal that the Sichuan basin significantly amplified low frequency ground motions, with a maximum amplification factor of 9.6 located at the Zhuwa depression, which has the deepest Quaternary sediments. Compared to the vertical component, the horizontal component of the ground motion demonstrates greater amplification factors. The coupling of the basin-edge effect, the rupture directivity effect, and the interference between the waves from different subfaults results in strong local ground motions at the basin edge areas, such as Dujiangyan and Mianzhu. For the studied frequency band, the Quaternary Chengdu plain mainly amplifies seismic waves above $0.3 \mathrm{~Hz}$, while the basin basement is sensitive to waves below $0.3 \mathrm{~Hz}$. The Quaternary Chengdu plain significantly amplifies wave amplitudes and changes the distribution features of strong ground motions.
\end{abstract}

Keywords Sichuan basin $\cdot$ Quaternary $\cdot 3 \mathrm{D} \cdot$ Wenchuan earthquake $\cdot$ Amplification effect · Spectral-element

Haiping Ding

haiping_ding@sina.com

1 Key Laboratory of Structure Engineering of Jiangsu Province, Suzhou University of Science and Technology, Suzhou 215011, China

2 Institute of Engineering Mechanics, China Earthquake Administration, Harbin 150080, China 


\section{Introduction}

The Ms 8.0 Wenchuan earthquake on 12 May 2008 caused a significant loss of life and structural damage. According to the Modified Mercalli Intensity map (Fig. 1; Yuan 2008), the cities located near the western Sichuan basin edge, such as Dujiangyan, Mianzhu, Anxian, and Jiangyou, suffered severe damage. It is shown in Fig. 1 that Dujiangyan, Mianzhu, and Anxian are located in the IX seismic intensity zone, and the IX intensity line demonstrates obvious bulges at Dujiangyan and Mianzhu. By using field survey and seismic records, Guo and Zhou (2010) investigated the effect of the local site conditions on the seismic disasters during the Wenchuan earthquake, and noticeable basin effects were observed. For instance, the seismic damages at the basin edge area are generally more severe than those in the basin-internal region. Numerous historical earthquakes and numerical studies also showed that the sedimentary basin can significantly amplify the ground motions within it (Anderson et al. 1986; Chen 2003; Lee et al. 2008).

Due to a lack of strong ground motion records in the basin, the numerical simulation method constitutes a major tool for investigating the basin effects of the Sichuan basin during the Wenchuan earthquake. Zhang et al. (2008) simulated the strong ground motion caused by this earthquake considering a three-dimensional (3D) earth structure, finite-fault rupture, and realistic surface topography. Bjerrum et al. (2010) studied the broadband strong ground shaking due to this earthquake using a hybrid method and two 1D layered models corresponding to the Tibetan Plateau and the Sichuan basin, respectively. Moreover, many numerical simulation studies of this earthquake based on 1D velocity structure model can also be found (Chavez et al. 2010; Meng and Shi 2011; Chang et al. 2012). It should be noted that these studies did not consider the complex Sichuan basin model and the Quaternary sediment. Although a global sediment layer model was incorporated in the

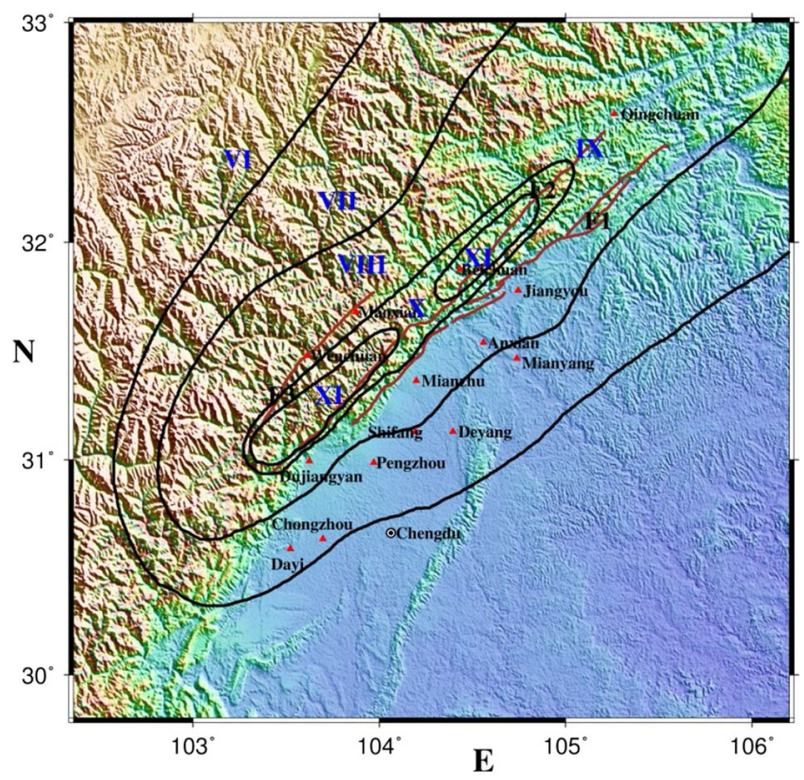

Fig. 1 Modified Mercalli Intensity map of the Wenchuan earthquake 
work of Zhang et al. (2008), it did not include the Quaternary sediment, and the $1^{\circ} \times 1^{\circ}$ spatial accuracy of this global sediment model is somewhat rough.

In this study, a three-dimensional Sichuan basin model is established first by incorporating the realistic surface topography, the Quaternary Chengdu plain, the sediment layer model, the basin crystalline basement, and the 1D crustal structure. The calculation region is shown in Fig. 2. Then the 3D long-period ( $\geq 2 \mathrm{~s}$ ) seismic responses of the Sichuan basin during the Wenchuan earthquake are simulated using a parallel spectral element method and the finite fault model proposed by Ji and Hayes (2008). The emphasis is put on the cause of the severe damage at the basin edge regions, such as Dujiangyan, Mianzhu, and Jiangyou; the influence of the Quaternary Chengdu plain on the strong ground motion; and the amplification behavior of the Sichuan basin in this earthquake. The wave propagation snapshot, synthetic waveform, distribution of peak ground velocity (PGV) and basin amplification factor are used to analyze the characteristics of the basin strong motion in detail.

\section{Sichuan basin model}

\subsection{The Quaternary sediment}

The Chengdu plain in front of the Longmenshan Mountain is a major Quaternary deposit region in the Sichuan basin, which is related to the formation and evolution process of the basin (Liu 1983). It is located at the western margin of the Sichuan basin (Fig. 3), with a maximum width and length of 80 and $200 \mathrm{~km}$, respectively, and a total area of more than $8400 \mathrm{~km}^{2}$. The Chengdu plain was formed in the Quaternary period, when glaciers were widely distributed. After the ablation of the glaciers of the northwestern mountains, a large volume of sediment was carried by the Minjiang and Tuojiang Rivers and deposited in the depression west of the Sichuan basin, and the Chengdu plain was finally formed.

During the 1980s, the hydrology and engineering geology of the Chengdu plain were comprehensively investigated by the Sichuan Institute of Geological Engineering

Fig. 2 Sketch map of the calculation area. The black solid lines denote the boundaries, and the long and short axes are defined as the $X$ and $Y$ axes, respectively. The black dashed lines indicate the Quaternary Chengdu plain, the red rectangle represents the surface projection of the causative fault of the 2008 Wenchuan earthquake, and the red star indicates the epicenter determined by the USGS. The brown lines indicate the fault traces that constitute the Longmenshan fault. F1 Guanxian-Jiangyou fault; $F 2$ Yingxiu-Beichuan fault; $F 3$ Maoxian-Wenchuan fault

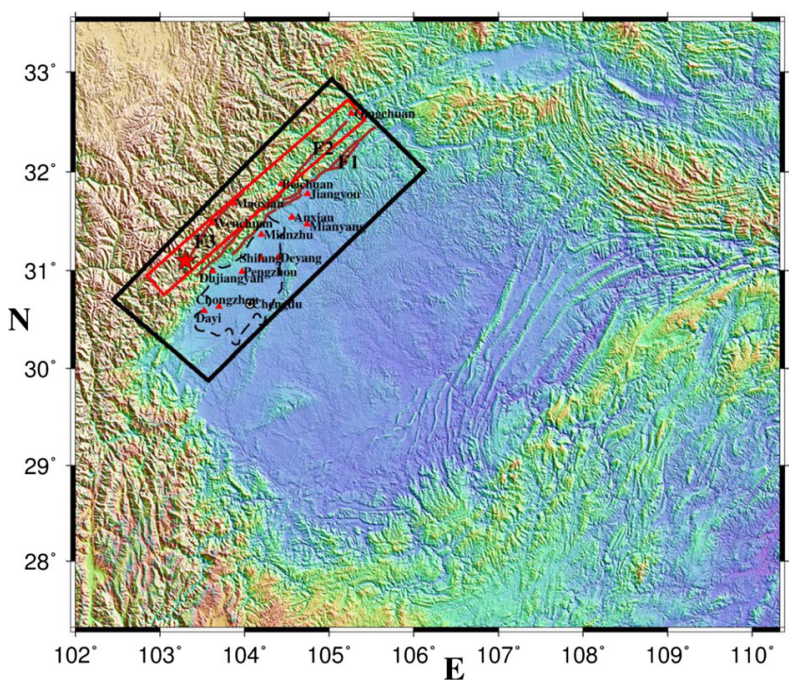




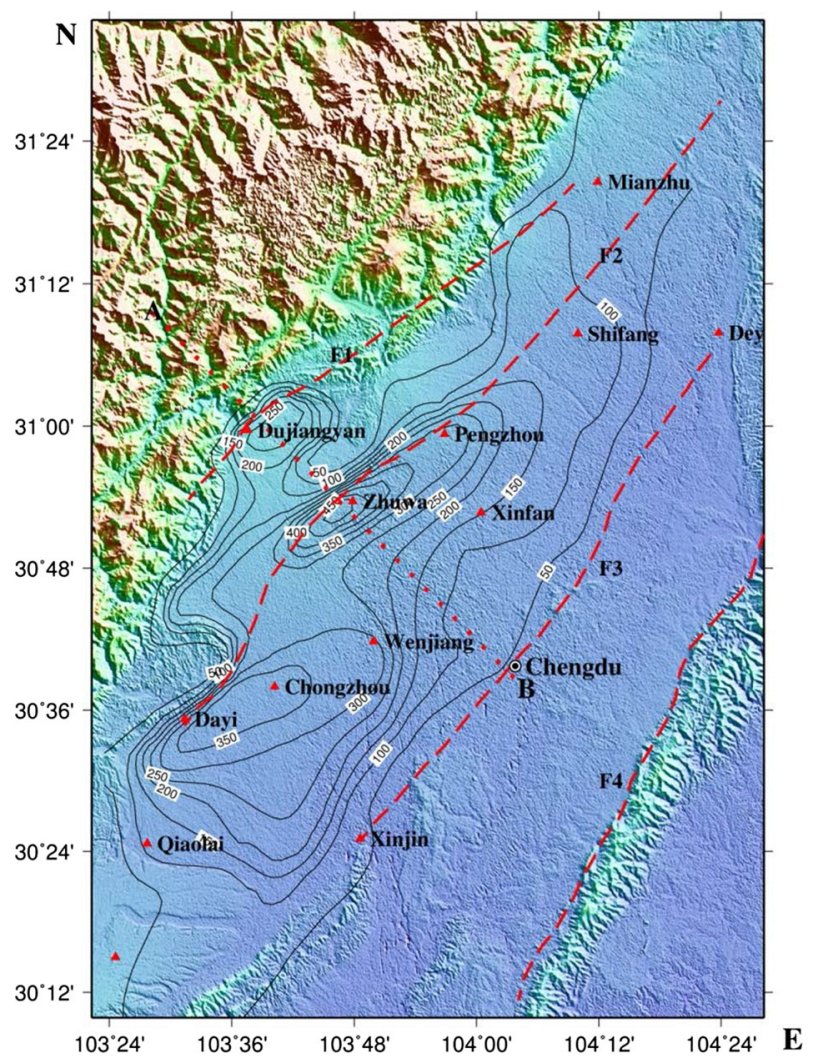

Fig. 3 Isopach map of the Quaternary sediments of the Chengdu plain (units $\mathrm{m}$ ) and the pseudoarray $\mathrm{AB}$ across the plain. F1 the Guankou fracture; F2 the Dayi-Zhuwa fracture; $F 3$ the Xinjin-Chengdu fracture; and F4 the Longquanshan fracture. Modified from He (1992)

Investigation, and numerous borehole and profile data were obtained. Based on these, Liu (1983) and He (1987, 1992) described a Quaternary sediment depth distribution of the Chengdu plain, as shown in Fig. 3. Some characteristics can be observed (Li and Zeng 1994): (1) the basement has an obvious asymmetrical shape, with a greater dipping angle at the western edge of the plain compared to the eastern edge; (2) the Chengdu plain can be further divided into the western, middle, and eastern depression regions. The western depression is located between the Guankou fault and the Dayi-Zhuwa fault, with a maximum depth of the Quaternary sediment of $253 \mathrm{~m}$ adjacent to Dujiangyan. The middle depression lies between the Dayi-Zhuwa fault and the Xinjin-Chengdu fault, where the deepest sediment $(541 \mathrm{~m})$ is found at Zhuwa, and the second deepest is located near Dayi. The eastern depression is located between the Xinjin-Chengdu and Longquanshan faults, with a relatively shallow Quaternary sediment of approximately $20 \mathrm{~m}$. The three deepest parts of the Chengdu plain will be referred to as the Dujiangyan bowl, the Zhuwa bowl and the Dayi bowl according to their locations. 


\subsection{The basin basement}

In previous numerical studies of the basin seismic effect, different subsurfaces were used as the basin basement, such as the crystalline basement (Komatitsch et al. 2004), the Tertiary basement (Lee et al. 2008), the isosurface of the $2.5 \mathrm{~km} / \mathrm{s} \mathrm{S}$-wave velocity (Olsen 2000), the isosurface of the $1.5 \mathrm{~km} / \mathrm{s} \mathrm{S}$-wave velocity (Day et al. 2008), and the Quaternary basement (Liu et al. 2015). The study of Stewart et al. (2005) showed that the basin basement depth varies from $100 \mathrm{~m}$ to more than $10 \mathrm{~km}$.

Song and Luo (1995) described a depth distribution of the crystalline basement for the Sichuan basin (Fig. 4) by incorporating the extradeep oil well data, the seismic logging data, the metamorphic rock data, and the seismic line data. We use this interface as the Sichuan basin basement. As shown in Fig. 4, the deepest part of the basement is probably located between Mianyang and Deyang, with a depth of more than $10 \mathrm{~km}$.

\subsection{Velocity structure}

Lu et al. (2012) and Rong et al. (2013) investigated the S-wave velocity $\left(\mathrm{V}_{\mathrm{s}}\right)$ structure of the Chengdu plain using the multi-channel surface wave analysis method and the borehole data, and it was found that the average shear wave velocity of the Chengdu plain at a depth of $30 \mathrm{~m}$ is approximately $280 \mathrm{~m} / \mathrm{s}$. Considering that the wave velocity generally increases with depth, a constant shear wave velocity of $500 \mathrm{~m} / \mathrm{s}$ in the Chengdu plain is used. The Pwave speed $\left(\mathrm{V}_{\mathrm{p}}\right)$ is obtained by multiplying $\mathrm{V}_{\mathrm{s}}$ by a coefficient of 2.2 (i.e., a Poisson ratio of 0.37). Since little is known about the attenuation of the Chengdu plain, a constant shear quality factor $\left(Q_{\mu}\right)$ value of 90 is used, based on the $Q_{u}$ value of the sediment of the Los Angeles basin (Komatitsch et al. 2004).

Referring to the global sediment layer model (Laske and Masters 1997), a deposit layer with a depth of $2 \mathrm{~km}$ is used in the simulations, with S- and P-wave speeds of 1.2 and $2.5 \mathrm{~km} / \mathrm{s}$, respectively (hereafter referred to as the near-surface sediment). The $Q_{\mu}$ value of the near-surface sediment is taken from the work of Zhao et al. (2011).

Fig. 4 Depth of the crystalline basement of the Sichuan basin model (unit $\mathrm{km}$ ). Modified from Song and Luo (1995)

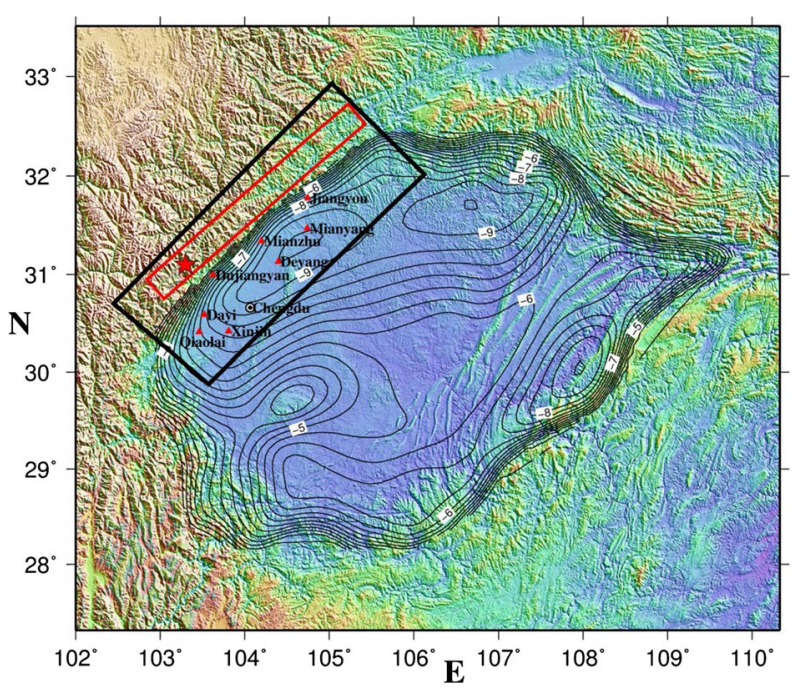


Wang et al. (2005) established a 2D crustal P-wave velocity structure model transecting the Tibetan Plateau and the Sichuan basin based on the seismic data. Within the basin, the P-wave speed from depth of $2 \mathrm{~km}$ to the basin basement adopt this model. Zhang and Yang (1983) found a $Q$ value of $800-1100$ in the Sichuan basin by using the coda waves. Based on this, a constant value of $Q_{\mu}=900$ is used for this layer. Due to a lack of data, a 1D crustal model is used outside the basin based on the model of Wang et al. (2005), with a P-wave speed obtained from the average value, and the depth chosen as the values of the Sichuan basin region. The $S$-wave speeds from the basin basement to the lower crust are computed by dividing $\mathrm{V}_{\mathrm{p}}$ by a coefficient of 1.732 (i.e., a Poisson solid is assumed), and the attenuations of the three crust layers are ignored.

The densities of each layer are estimated from the P-wave velocity by using the empirical relation (Ludwig et al. 1970), and the bulk quality factors $\left(Q_{\kappa}\right)$ of each layer are set to infinity in the simulations. The velocity structure parameters are listed in Table 1.

\subsection{Sichuan basin model}

Based on the above data, we established a 3D Sichuan Basin model (Fig. 5, referred to as the "Basic model" hereafter), with a size of $340 \mathrm{~km} \times 152 \mathrm{~km}$ horizontally and from +5.59 to $-33 \mathrm{~km}$ vertically. We incorporated the surface topography based on the ASTER Global Digital Elevation Model (ASTER GDEM) generated from the data collected by the Advanced Spaceborne Thermal Emission and Reflection Radiometer, which provides a resolution of $30 \mathrm{~m}$ for the region. To accommodate a finer mesh near the Quaternary boundary, a mesh size of $50 \mathrm{~m}$ vertically was used in the Chengdu plain. Two consecutive mesh triplings were used at the Quaternary boundary and a depth of $\mathrm{z}=-2400 \mathrm{~m}$, in accordance with the corresponding increases in wave speeds. The mesh contains a total of $2,927,798$ spectral elements. A polynomial degree of $N=4$ was used to sample the wave field, so each spectral element contains $(\mathrm{N}+1)^{3}=125$ Gauss-Lobatto-Legendre points, and the mesh contains a total of 193,529,965 grid points.

\section{Source model and calculation method}

After the Wenchuan earthquake, numerous source rupture models were obtained by using the inversion method and different data (Wang et al. 2008; Zhao et al. 2009; Zhang et al. 2009; Ji and Hayes 2008; Nakamura et al. 2010; Hartzell et al. 2013). In this study, the source model of Ji and Hayes (2008) was used, which was derived from the inversion of the teleseismic body and surface wave records and was shown to be compatible with these

Table 1 Velocity structure of the Sichuan basin model

\begin{tabular}{lllllr}
\hline & Depth $(\mathrm{km})$ & $V p(\mathrm{~km} / \mathrm{s})$ & $V s(\mathrm{~km} / \mathrm{s})$ & Density $\left(\mathrm{kg} / \mathrm{m}^{3}\right)$ & $\mathrm{Qu}$ \\
\hline Quaternary sediment & $<0.54$ & 1.1 & 0.5 & 1900 & 90 \\
Near-surface sediment & $<2$ & 2.5 & 1.2 & 2100 & 500 \\
Basin basement & $<12$ & 3.9 & 2.25 & 2380 & 900 \\
Upper crust & 24 & 6.0 & 3.47 & 2720 & 9999 \\
Middle crust & 30 & 6.3 & 3.64 & 2790 & 9999 \\
Lower crust & 33 & 7.0 & 4.04 & 2970 & 9999 \\
\hline
\end{tabular}




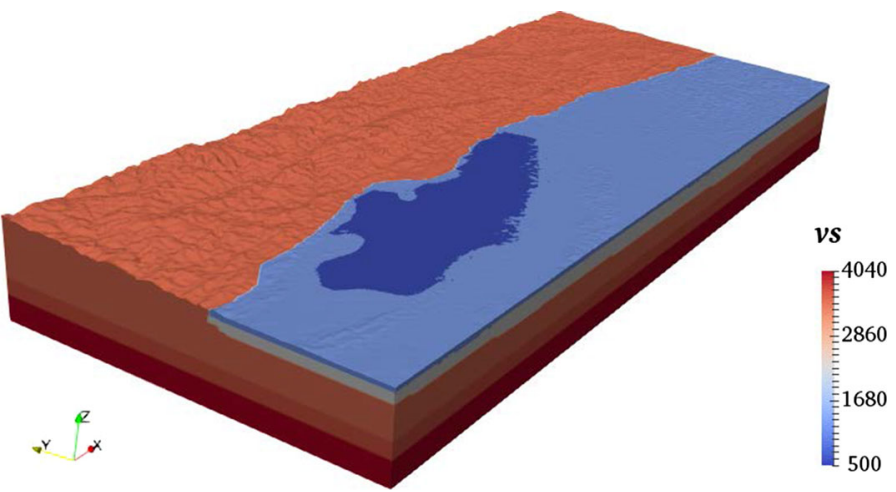

Fig. 5 3D Sichuan basin model. The dark and light blue regions denote the Quaternary Chengdu plain and the near-surface sediment, respectively. Shear-wave velocities $(\mathrm{m} / \mathrm{s})$ of each layer are shown in the right color bar

data over a range of frequencies from 0 to $0.5 \mathrm{~Hz}$. The fault rupture length and width are 315 and $40 \mathrm{~km}$, respectively, with a corresponding subfault size of $15 \times 5 \mathrm{~km}^{2}$. The fault strike and dip angle are $229^{\circ}$ and $33^{\circ}$, respectively. For simplicity, we used a constant rake of $141^{\circ}$ provided by the USGS, which was also used in the numerical studies of Chavez et al. (2010). The epicenter is located at $\left(103.3^{\circ} \mathrm{E}, 31.1^{\circ} \mathrm{N}\right)$. Figure 6 demonstrates the slip distribution along the fault surface.

It is shown in Fig. 6 that the rupture process contains two major asperities, one lying near Wenchuan, and the other lying between Beichuan and Qingchuan, with a maximum slip of over $9 \mathrm{~m}$. The rupture arrival time and the rise time of each subfault are determined from empirical studies. Somerville et al. (1999) found that the average rupture velocity varies from 2.4 to $3.0 \mathrm{~km} / \mathrm{s}$ by studying 15 crustal earthquakes. The study of Schmedes et al. (2010) showed that rise time is strongly correlated with slip. Abe (1975) found that the slip velocity is constant for several earthquakes and in the range of $0.1-1 \mathrm{~m} / \mathrm{s}$. We assumed a constant rupture velocity of $2.7 \mathrm{~km} / \mathrm{s}$, and the rupture arrival time at each subfault was obtained by dividing the distance from its center to the hypocenter by the

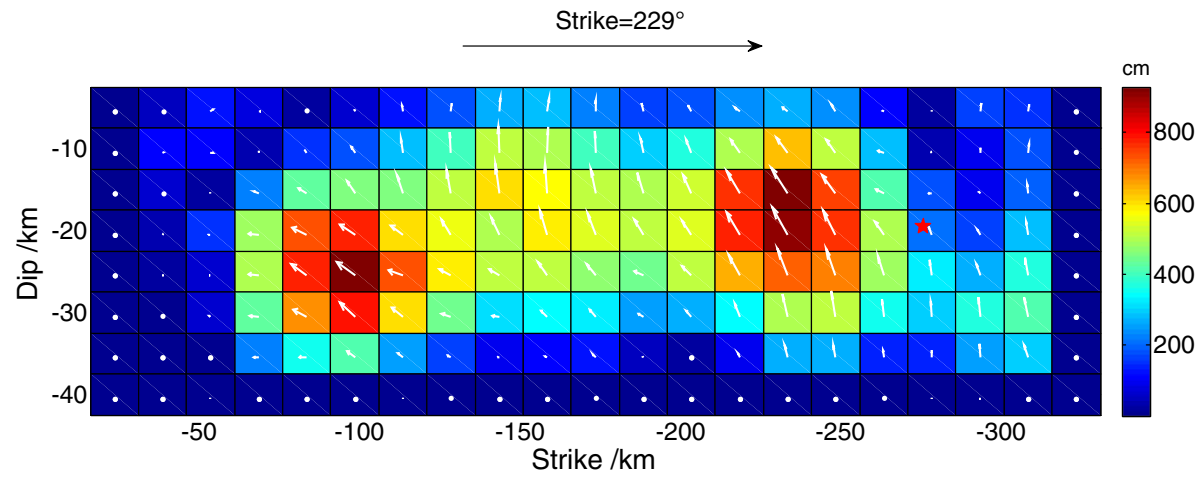

Fig. 6 Slip distribution of the 12 May 2008 Wenchuan earthquake proposed by Ji and Hayes (2008). The star indicates the source, and the slip amount of each subfault is shown by colors from blue to red 
rupture velocity. We used the same slip velocity of $0.8 \mathrm{~m} / \mathrm{s}$, and the rise time of each subfault is set to vary across the fault plane, depending on the amount of slip on it.

The spectral element method (SEM) and parallel computing technique are used to simulate the wave propagation behavior of the Sichuan Basin during the Wenchuan earthquake. Compared with the finite-element and finite-difference methods, and for the same accuracy level, the SEM is considerably efficient for its lower number of grid points per minimum wavelength. Absorbing boundary conditions (Clayton and Engquist 1977) are used at all boundary surfaces except at the free surface. Based on the rule-of-thumb that roughly five points per minimum wavelength that could be correctly propagated in the model are needed for the SEM, the maximum resolved frequency is about $0.5 \mathrm{~Hz}$ for the current mesh and velocity model. The simulations are performed on a DELL PRECISION cluster (30 nodes, 240 processors) with a time step of $0.8 \mathrm{~ms}$, and the total computing time is about $40 \mathrm{~h}$ for a $160 \mathrm{~s}$ simulation.

\section{Simulation result}

\subsection{Wave field snapshot}

The snapshots of the $X$ component velocity at the surface are shown in Fig. 7. At about $19.2 \mathrm{~s}$, the wave front enters the basin. Due to the low velocity sediment, amplitudes in the basin are obviously amplified. In addition, the wave fronts are clearly delayed and distorted inside the basin. At about $25.6 \mathrm{~s}$, the waves from different sub-ruptures arrive at Dujiangyan almost simultaneously, resulting in wave superposition and constructive interference, which considerably amplifies the regional ground vibrations. At $38.4 \mathrm{~s}$, the waves pass through Zhuwa, which has the thickest Quaternary sediments, and the seismic waves trapped in the Dujiangyan bowl travel back and forth inside it. Meanwhile, in the Zhuwa bowl, obvious surface waves are generated adjacent to the edge, which then interfere with the direct body waves. In addition, the northeastern wave front reaches Mianzhu. Because of the coupling effect of the rupture directivity effect, the basin effect, and interference between different sub-rupture waves, obvious strong ground motions can be found from Mianzhu to Hanwang. At about $60.8 \mathrm{~s}$, the wave front arrives at Anxian and Jiangyou. Strong motions can also be found in these regions for the same reason as that in Mianzhu. Additionally, the surface waves generated in the Dayi bowl can be observed, and the surface waves in the Zhuwa bowl become stronger. Interference between the surface and body waves make wave propagations inside the bowls complex, which can be clearly seen at the $70.4 \mathrm{~s}$ snapshot. For instance, constructive and destructive interference regions show alternant distributions. At $124.8 \mathrm{~s}$, the seismic waves propagate continually into the Sichuan basin. Two obvious interference bands can be found inside the basin, where the ground motion amplitudes are obviously larger than the surrounding areas. After $136 \mathrm{~s}$, most of the basin internal ground motions attenuate to a relatively low level, while interference regions and lasting vibrations can still be found in some parts of the Chengdu plain.

\subsection{Synthetic seismogram}

As shown in Fig. 3, the profile $\mathrm{AB}$ along the $\mathrm{Y}$ axis transects the Zhuwa bowl and Dujiangyan bowl, with maximum sediment depths of 541 and $253 \mathrm{~m}$, respectively. 
$\mathrm{t}=11.2 \mathrm{~s}$

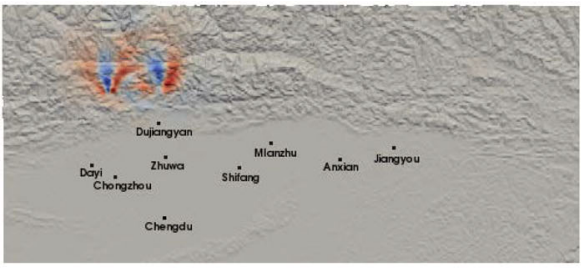

$\mathrm{t}=19.2 \mathrm{~s}$

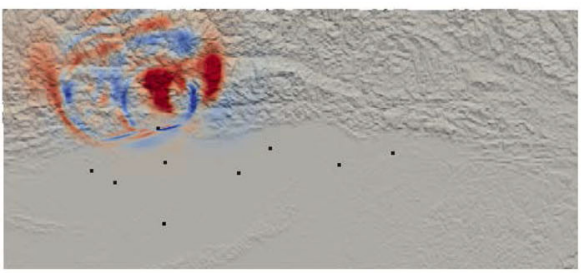

$\mathrm{t}=25.6 \mathrm{~s}$

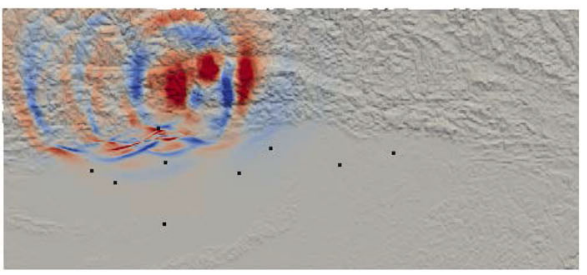

$\mathrm{t}=38.4 \mathrm{~s}$

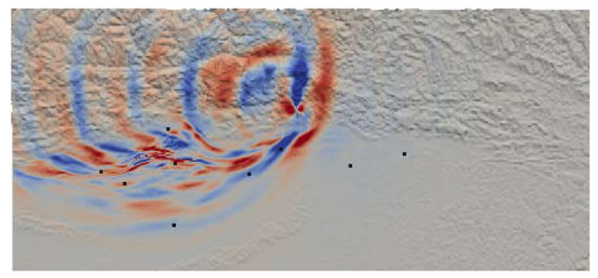

$\mathrm{t}=60.8 \mathrm{~s}$

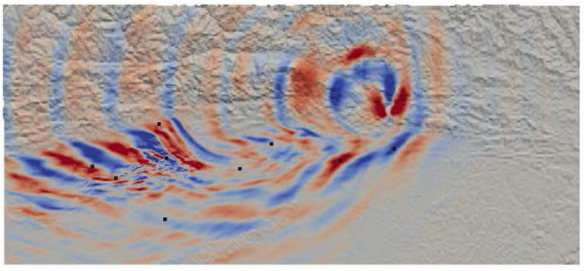

$\mathrm{t}=70.4 \mathrm{~s}$

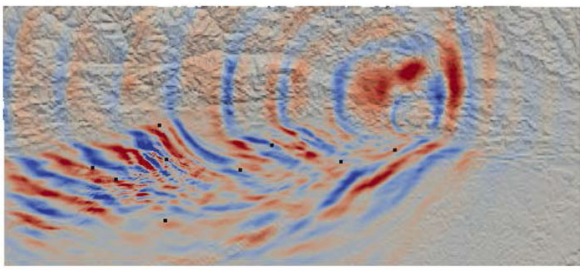

$\mathrm{t}=124.8 \mathrm{~s}$

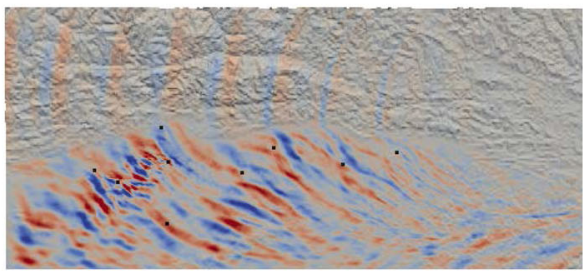

$\mathrm{t}=136 \mathrm{~s}$

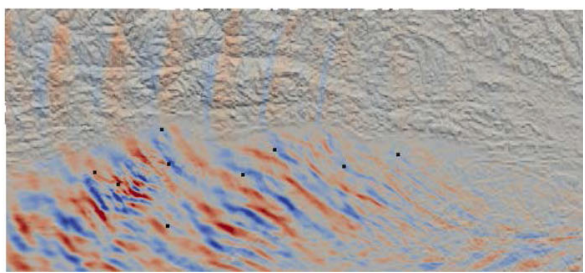

Fig. 7 Snapshots of the $\mathrm{X}$ component velocity wavefield. The red (blue) shading depicts the positive (negative) particle velocity. Some typical cities, such as Dujiangyan, Zhuwa, and Mianzhu are also shown in the snapshot by the black points

Figure 8 shows the synthetic velocity seismograms along profile $\mathrm{AB}$, which are band-pass filtered from 0.05 to $0.5 \mathrm{~Hz}$. Also shown are the velocity structure and PGV distribution along this profile. From Fig. 8, we observe the following.

1. The $\mathrm{X}$ and $\mathrm{Y}$ component ground motions are obviously influenced by the basin seismic effect. It is obvious that the synthetic waveforms of the basin internal sites have relatively larger amplitudes and longer durations compared to the stations outside of the basin. At the bowl's edge, surface waves are generated and propagate inward. Interference between the surface waves and body waves significantly amplifies the ground motions inside the bowl. Additionally, multi- reflected and scattered body waves, surface waves, and waves from different sub-faults make the seismograms quite complex. 
(a)

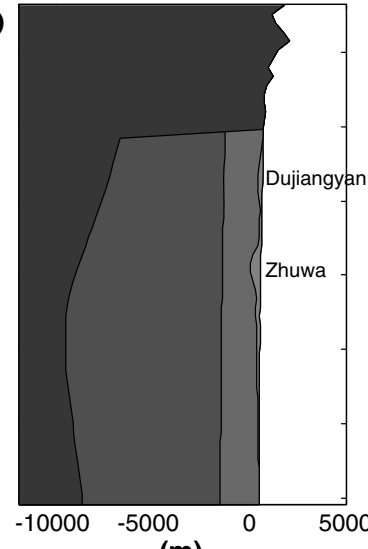

(m)

(b)

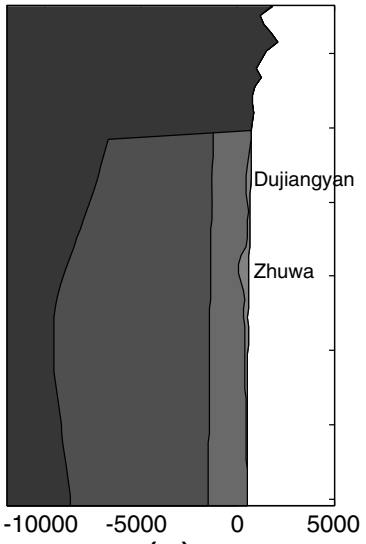

(m)

(c)

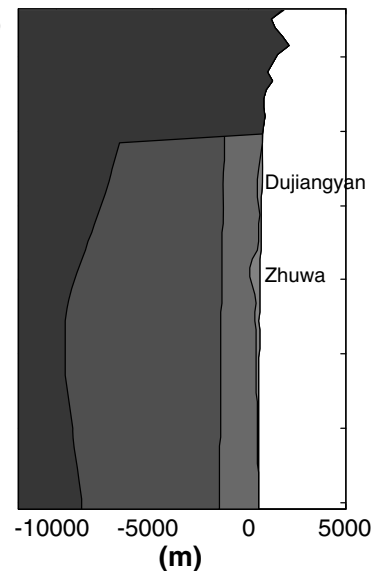

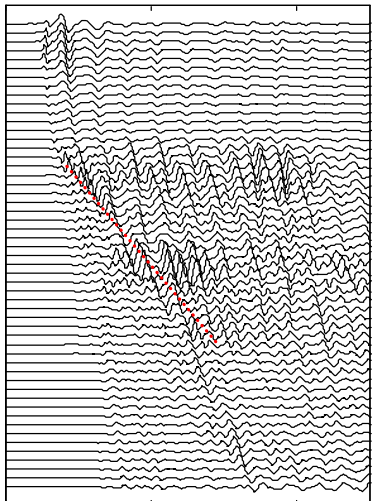

50

time (s)
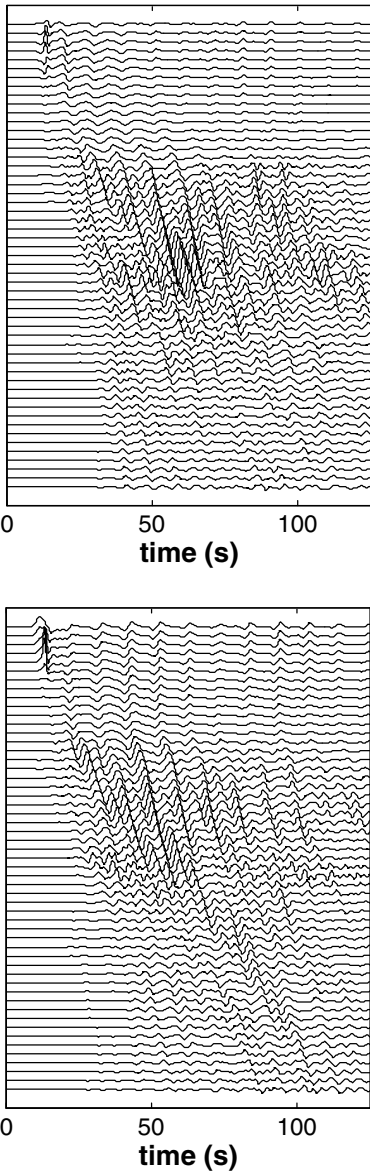
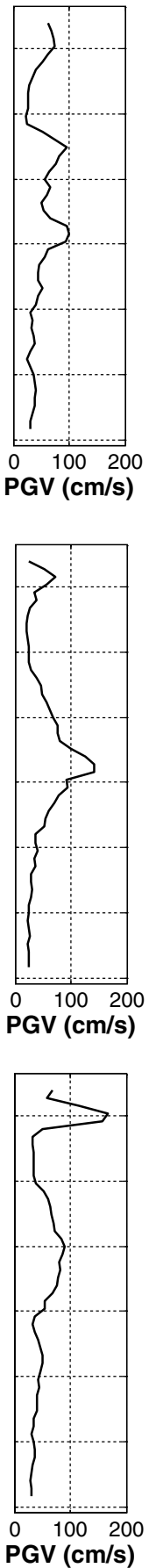

Fig. 8 Synthetic velocity waveforms in the $\mathbf{a} \mathrm{x}$ component, $\mathbf{b} \mathrm{y}$ component, and $\mathbf{c} \mathrm{z}$ component for the profile $\mathrm{AB}$ (bandpass filtered from 0.05 to $0.5 \mathrm{~Hz}$ ). The red dashed line indicates the surface wave phase. The constituted layers and the PGV values along the profile $\mathrm{AB}$ are also shown in each subfigure 
2. For the $\mathrm{X}$ component, the largest amplitude of the Dujiangyan bowl is comparable to that of the Zhuwa bowl. For the Y component, the velocity in the Zhuwa bowl is much greater than in the Dujiangyan bowl. It should be noted that the largest values in these two bowls are not situated at the deepest parts, but near the bowl's edge that is opposite to the incident direction. In addition, the Y component velocity amplitudes at the transition area between the two bowls are also relatively large and even exceed the amplitudes in the Dujiangyan bowl, although the corresponding soil depth is only about $100 \mathrm{~m}$. This may be related to the coupling effect between the two adjacent bowls.

3. The $\mathrm{Z}$ component ground motions are not so obviously influenced by the basin effect. The strongest shaking is located at the western mountain top, and in the basin, the strong shaking mainly occurs at the transition region between Dujiangyan and Zhuwa bowls, rather than at the deepest parts.

4. Surface topography effect can be clearly observed from the velocity seismograms of all three components, i.e., the ground motion amplitudes at the mountain summit are much larger than those at the mountain foot.

\subsection{PGV distribution}

Figure 9 shows the PGV distribution of the calculation region of the east, north, and vertical components (all results are band-pass filtered between 0.05 and $0.5 \mathrm{~Hz}$ ). Obvious hanging wall effect can be observed in the simulation results, and two strong ground motion regions are found in the hanging wall area. One is located from Wenchuan to Maoxian, the other is near Beichuan. These locations are dominated by the two asperities on the fault. Meanwhile, the simulation results show obvious rupture directivity effect; that is, the ground motions in front of the rupture direction are much stronger than those behind it.

In addition to the hanging wall area, large PGVs can also be found in the Sichuan basin, which are mainly located in the Chengdu plain and the basin edge region. The largest PGV is located at the Zhuwa bowl, which has the deepest Quaternary sediment. Although behind the rupture direction, the PGV of the Dayi bowl is larger than that of the Dujiangyan bowl, which is located in front of the rupture direction but has shallower sediment. Additionally, a strong ground motion belt can be found along the basin edge, which is roughly in agreement with the seismic damage survey result. The wave field snapshots show that it caused by the basin edge effect, the rupture directivity effect, and the constructive interference between waves from different subfaults. From the basin edge to the basin inside, the ground motions attenuate significantly. For the vertical component, the mainly thrust source model used makes the shaking amplitudes at the hanging wall obviously larger than the horizontal component. In the Sichuan basin, vertical strong ground motions are not in accordance with the sediment depth, and regional strong ground motions are found near Mianzhu, Anxian and Jiangyou. 

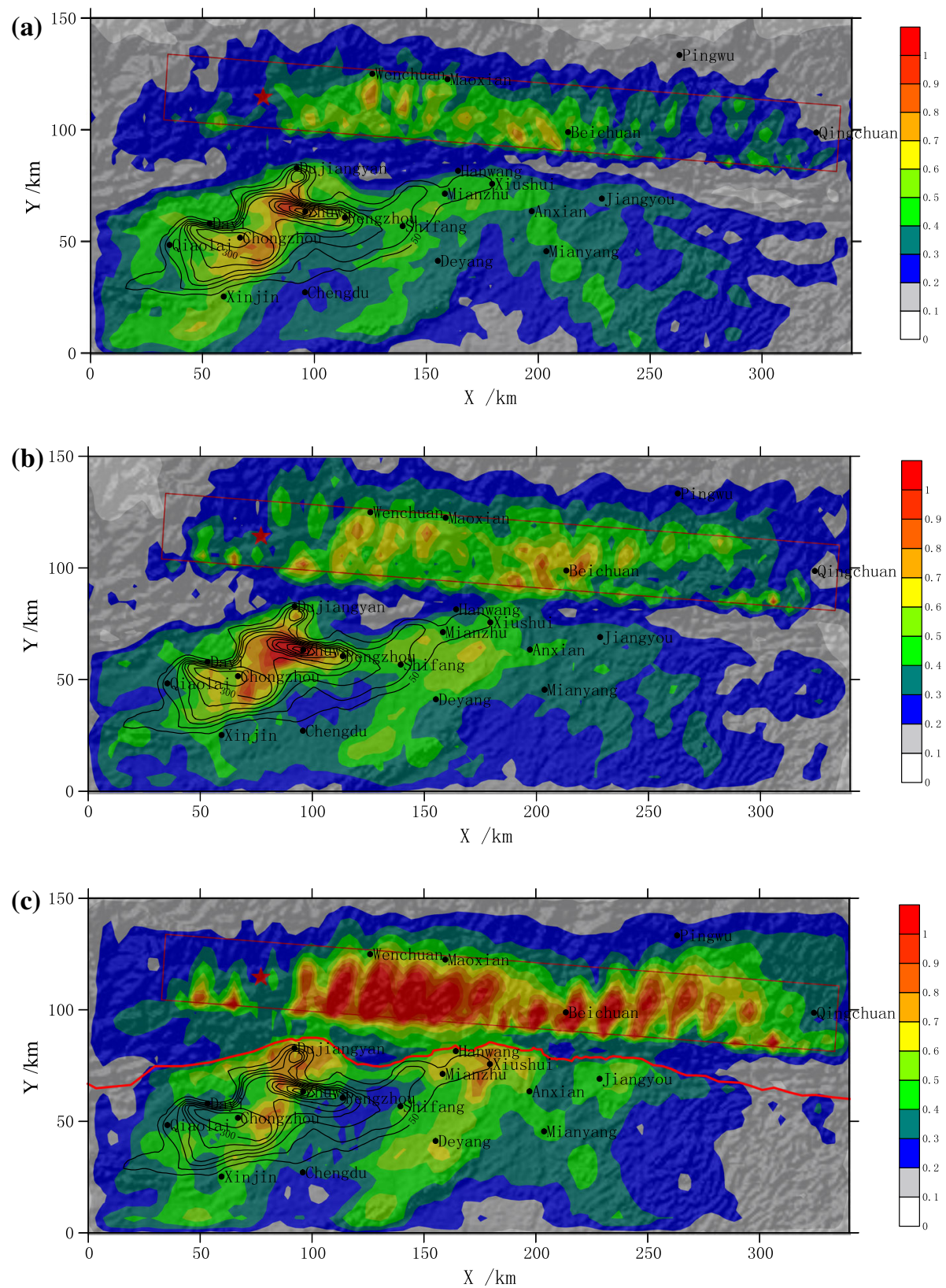

Fig. 9 The peak ground velocities in the $\mathbf{a}$ east component, $\mathbf{b}$ north component, and $\mathbf{c}$ vertical component. The black solid line indicates the depth distribution of the Quaternary Chengdu plain deposits. The red rectangle denotes the surface projection of the causative fault, and the star indicates the epicenter 


\section{Discussion}

\subsection{Amplification factor of the Sichuan basin}

The basin amplification factor (AF) is defined as the ratio between the PGV of the basic model and that of the model without the Sichuan basin (Fig. 10, which is referred to as the "rock site model" in the following), and the other parameters keep unchanged.

Figure 11a-c show the east, north, and vertical components of the PGV amplification factor distributions within the basin, respectively. For the east component, large AFs are concentrated in the Chengdu plain and regions with a basement depth of more than $9 \mathrm{~km}$. The largest $\mathrm{AF}$ is 9.64, which is located at the edge of Zhuwa bowl. For the north component, the AF distribution is generally similar to that of the east component, except that the large AFs shift closer to the basin edge. The largest AF is 9.4 and occurs at the deepest part of the Zhuwa bowl. In addition, for the north component, the Dujiangyan bowl shows an obviously larger AF compared with that of the east component (Fig. 11a). For the vertical component, the AFs are much smaller in comparison to those of the horizontal components. The largest AF is 5.0 and is located at $(125,15 \mathrm{~km})$. In contrast, the AFs at the Zhuwa and Dayi bowls are only about 3-4.

\subsection{Frequency-dependent basin amplification}

Basin effects may depend on the frequencies of the seismic waves. We compute the basin amplification factors for the seismic wave frequencies between 0.05 and $0.5 \mathrm{~Hz}$. Figure 12 shows the results for the east component. Below $0.2 \mathrm{~Hz}$, the basin amplification effect is controlled by the basin basement depth. The large AFs are located roughly near the deepest basement areas, and the Chengdu plain demonstrates an unobvious amplification. For wave frequencies from 0.2 to $0.3 \mathrm{~Hz}$, the AFs of the three bowls in the basin become stronger. Above $0.3 \mathrm{~Hz}$, the AFs grow significantly larger, and the effect of the Quaternary sediment makes the AF distribution more and more complex. In contrast, the influence of the basin basement depth becomes negligible. The north component shows a similar frequencydependent amplification pattern as that of the east component.

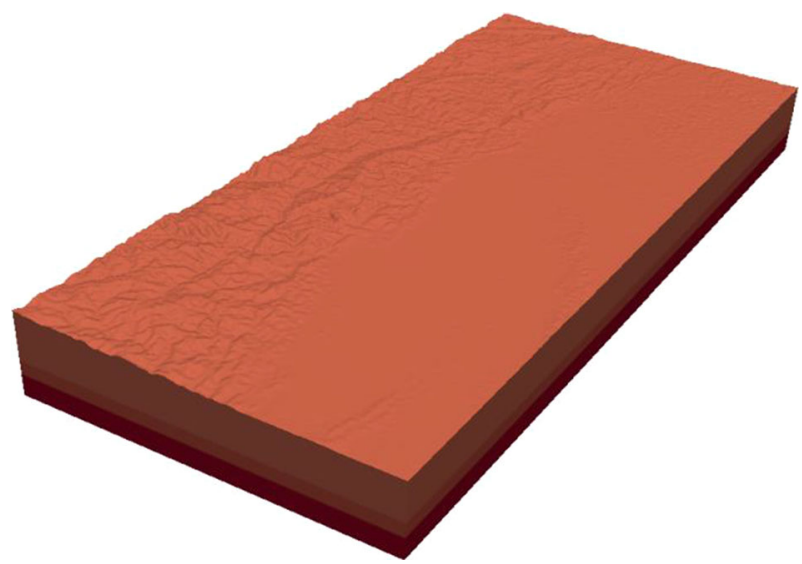

Fig. 10 The "rock site model" without the Sichuan basin 

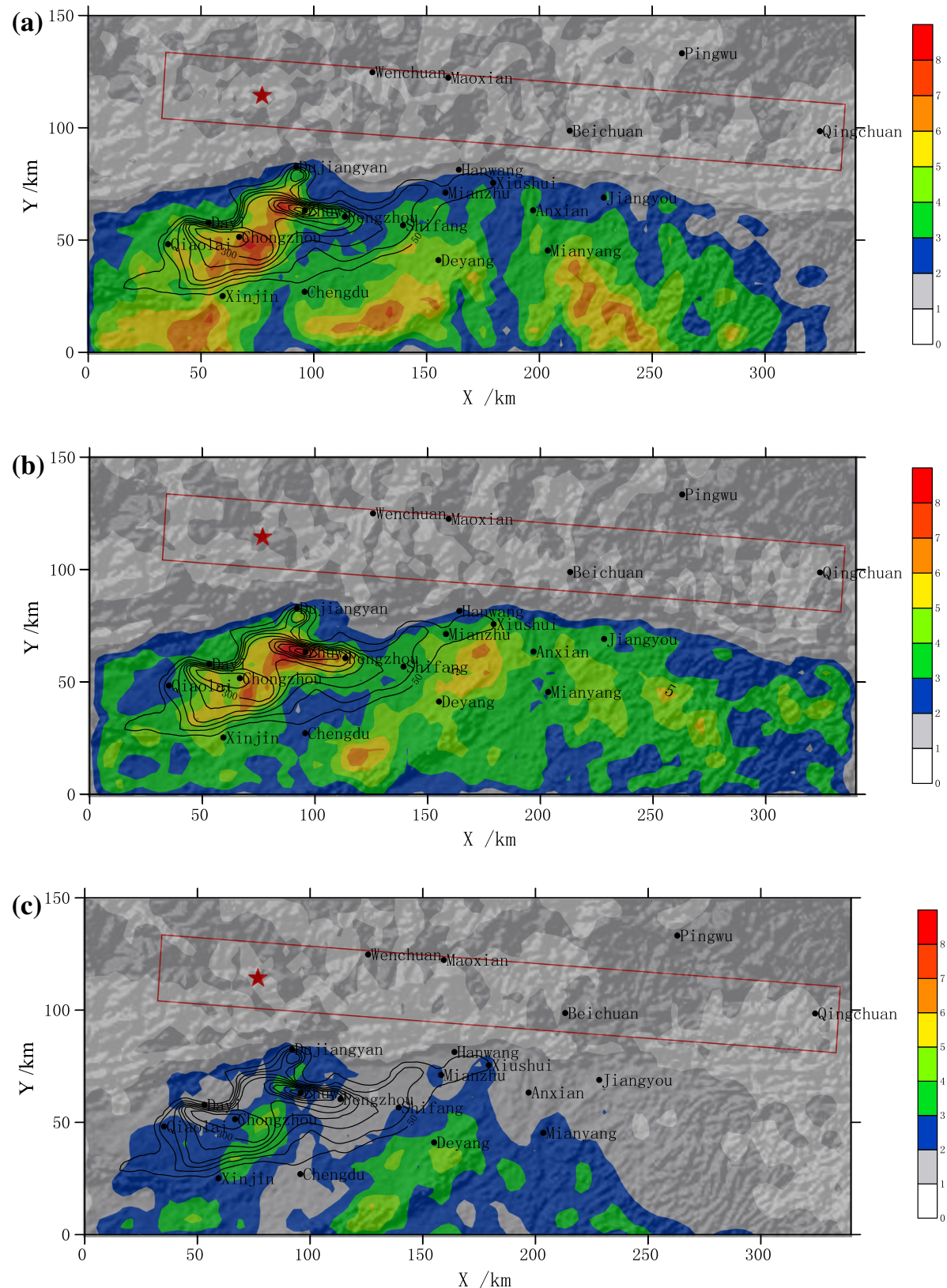

Fig. 11 The PGV amplification factor of the a east component, b north component, and c vertical component. The black solid line indicates the depth distribution of the Quaternary Chengdu plain deposits. The red rectangle denotes the surface projection of the causative fault, and the star indicates the epicenter

These results may be related to the relative lengths of the incident seismic waves and the size of the basin basement. For instance, for a wave frequency of $0.1 \mathrm{~Hz}$, the shear wave length is $34.7 \mathrm{~km}$ before entering the basement, which is 3.5 times of the largest basement 

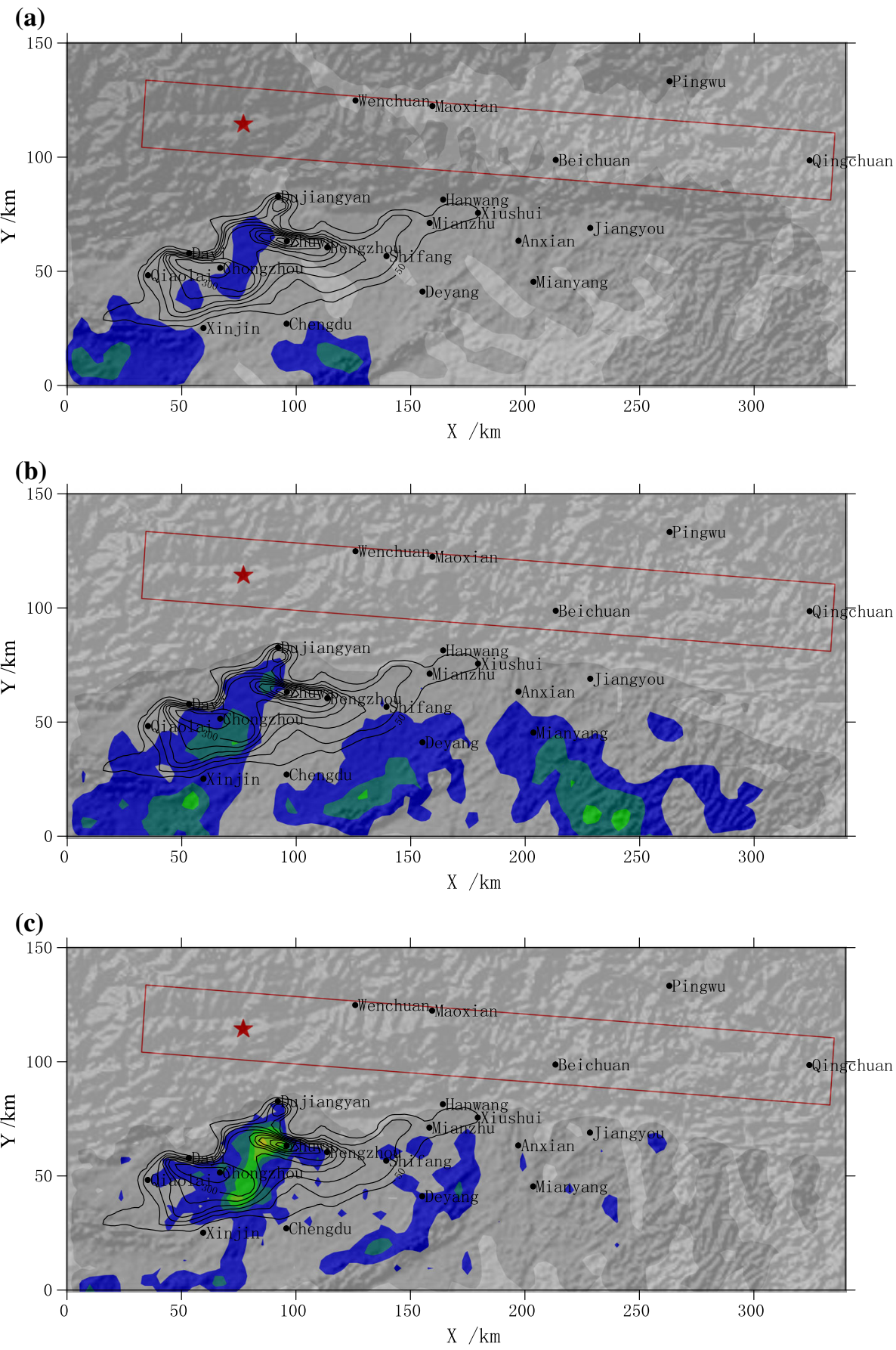

Fig. 12 PGV amplification factor of the east component for different frequencies. a $0.05-0.1 \mathrm{~Hz}$, b $0.1-0.2 \mathrm{~Hz}$, c $0.2-0.3 \mathrm{~Hz}$, d $0.3-0.4 \mathrm{~Hz}$, e $0.4-0.5 \mathrm{~Hz}$ 
(d)

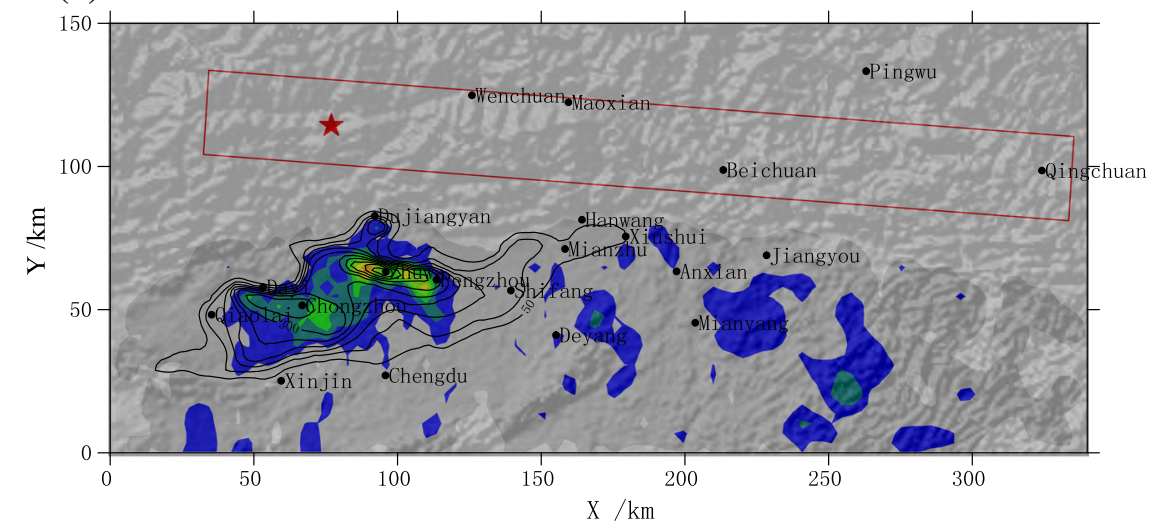

(e)

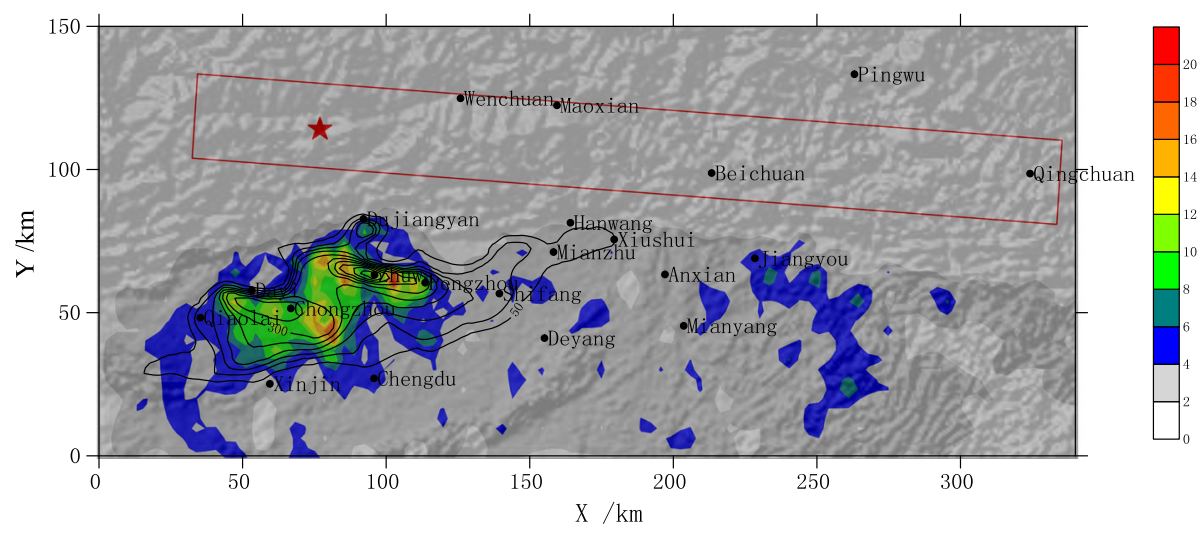

Fig. 12 continued

depth (approximately $10 \mathrm{~km}$ ). After entering the basement, the wave length changes to $12-22 \mathrm{~km}$, which is as large as 24 times the largest Quaternary sediment depth. Consequently, the wave with a $0.1 \mathrm{~Hz}$ frequency has no obvious amplification effect in the Chengdu plain.

\subsection{Comparison of synthetic PGV distribution with Mercalli modified intensity}

The comparison of the maximum synthetic velocity patterns in the north component with the Mercalli modified intensity (MMI) isoseist, observed mainly on and in the vicinity of the rupture zone of the 2008 Wenchuan earthquake (Yuan 2008), is presented in Fig. 13. It is shown that the synthetic large PGVs globally correspond with the intensity map. For example, an intensity of VIII was observed adjacent to the basin edge. Similar patterns can also be found in the simulated results. In addition, the regional 3D synthetic PGVs are largely in accordance with the intensity distribution features both in the basin internal region and in the hanging wall region of the fault. In the hanging wall, the largest PGV value $(>0.8 \mathrm{~m} / \mathrm{s})$ is in the range of the maximum velocity of an MMI of $\mathrm{X}$ according to the 


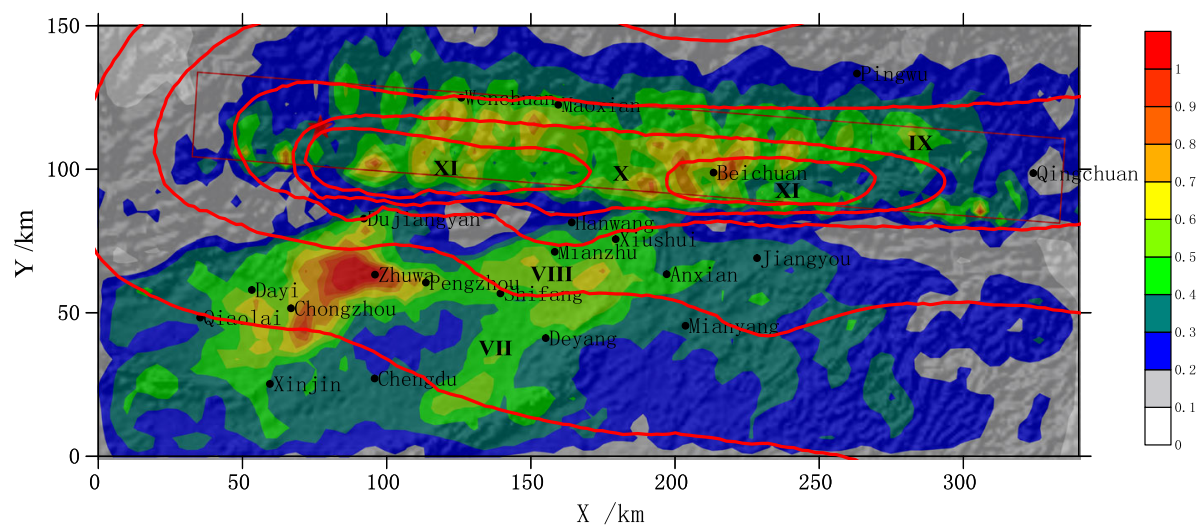

Fig. 13 Comparison of the Mercalli modified intensity isoseist of the 2008 Wenchuan earthquake with the simulated north component PGV of the basic model

Chinese seismic intensity scale $(0.72-1.41 \mathrm{~m} / \mathrm{s})$. However, there is a discrepancy at the Zhuwa bowl, where the largest synthetic PGV is found, but it is not shown in the MMI isoseist. Considering that the MMI is an overall result, we think that the comparison of the calculated PGV results with the MMI of the 2008 Wenchuan event are generally reasonable.

\section{Conclusions}

In this study, a 3D Sichuan basin model was first established based on the Quaternary sediment, the near surface layer, the crystalline basin basement, the crustal velocity structure and the real surface topography. Then the wave propagation behavior within the Sichuan basin during the Wenchuan earthquake was analyzed by using the spectral element method and the finite fault model. The wave propagation snapshot, synthetic seismogram, peak ground velocity, and amplification factor distribution within the basin were investigated. The following basic conclusions from the analyses can be reached:

1. The soft sediment in the Sichuan basin results in waves from different subfaults that meet at the basin edge area, leading to constructive interference there. Coupling with the basin edge effect, i.e., amplification effect due to the interference between the direct body wave and the basin-induced surface wave, and with the rupture directivity effect, the wave motions in the basin edge regions are significantly amplified. This may be a main cause of the severe damage at the basin edge areas such as Dujiangyan, Mianzhu, and Jiangyou.

2. The horizontal component of the ground motions is greatly influenced by the basin. The ground motion within the basin can be amplified by a factor of up to 9.6, and it is located at the Zhuwa bowl, which has the deepest Quaternary sediment. However, the vertical component of the ground motions is not so sensitive to the basin amplification effect, and is dominated by the surface topography effect; that is, seismic motions at the mountain summit are considerably stronger than those at the mountain foot and in the basin. 
3. The Quaternary Chengdu plain has a significant effect on the basin internal ground motion. A great deal of wave energy is trapped in the plain, leading to considerably larger shaking amplitude and longer duration time.

4. In the simulated frequency band, the Quaternary Chengdu plain mainly influences ground motions above $0.3 \mathrm{~Hz}$, and the Sichuan basin basement is apt to amplify seismic waves below $0.3 \mathrm{~Hz}$.

In addition, the source model used in the simulations is obtained from teleseismic records. However, the near field ground motions are sensitive to the detailed source rupture process. So the source model inverted from the near field data is needed to simulate the basin amplification behavior in the Sichuan basin in the future.

Acknowledgements The authors would like to express their appreciation to two anonymous reviewers for their constructive comments to improve the manuscript. This research is supported by the National Natural Science Foundation of China under Grant Nos. 51278323 and 51378479.

Open Access This article is distributed under the terms of the Creative Commons Attribution 4.0 International License (http://creativecommons.org/licenses/by/4.0/), which permits unrestricted use, distribution, and reproduction in any medium, provided you give appropriate credit to the original author(s) and the source, provide a link to the Creative Commons license, and indicate if changes were made.

\section{References}

Abe K (1975) Static and dynamic fault parameters of the Saitama earthquake of July 1, 1968. Tectonophysics 27(3):223-238

Anderson JG, Bodin P, Brune JN et al (1986) Strong Ground Motion from the Michoacan, Mexico, Earthquake. Science 233(4768):1043-1049

Bjerrum LW, Sørensen MB, Atakan K (2010) Strong ground-motion simulation of the 12 May 2008 Mw 7.9 Wenchuan earthquake, using various slip models. Bull Seismol Soc Am 100(5B):2396-2424

Chang Y, Zhou H, Yu YX (2012) Strong ground motion simulation of the Wenchuan earthquake. Acta Seismol Sin 34(2):224-234 (in Chinese)

Chavez M, Cabrera E, Madariaga R et al (2010) Low-frequency 3D wave propagation modeling of the 12 May 2008 Mw 7.9 Wenchuan earthquake. Bull Seismol Soc Am 100(5B):2561-2573

Chen KC (2003) Strong ground motion and damage in the Taipei basin from the Moho reflected seismic waves during the March 31, 2002, Hualien, Taiwan Earthquake. Geophys Res Lett 30:1151-1154

Clayton R, Engquist B (1977) Absorbing boundary conditions for acoustic and elastic wave equations. Bull Seismol Soc Am 67(6):1529-1540

Day SM, Graves R, Bielak J et al (2008) Model for basin effects on long-period response spectra in southern California. Earthq Spectra 24(1):257-277

Guo E, Zhou XY (2010) Study on basin effects of Wenchuan earthquake. J Disaster Prev Mitig Eng 30(4):459-465 (in Chinese)

Hartzell S, Mendoza C, Ramirez-Guzman L et al (2013) Rupture history of the 2008 Mw 7.9 Wenchuan, China, earthquake: evaluation of separate and joint inversions of geodetic, teleseismic, and strongmotion data. Bull Seismol Soc Am 103(1):353-370

He YW (1987) On the formation of the Chengdu baisn (plain). Reg Geol China 2:169-176 (in Chinese)

He YW (1992) The age of formation of the Chengdu basin and features of its early deposits. Geol Rev 38(2):149-156 (in Chinese)

Ji C, Hayes G (2008) Source model of the May 12th 2008 Wenchuan earthquake. http://earthquake.usgs. gov/eqcenter/eqarchives/poster/2008/20080512.php

Komatitsch D, Liu Q, Tromp J et al (2004) Simulations of ground motion in the Los Angeles basin based upon the spectral-element method. Bull Seismol Soc Am 94(1):187-206

Laske G, Masters G (1997) A global digital map of sediment thickness. http://igppweb.ucsd.edu/ gabi/ sediment.html\#sed

Lee SJ, Chen HW, Huang BS (2008) Simulations of strong ground motion and 3D amplification effect in the Taipei basin by using a composite grid finite-difference method. Bull Seismol Soc Am 98(3):1229-1242 
Li Y, Zeng YF (1994) On the sedimentary response to thrusting of Longmenshan thrust belt in Chengdu basin. J Mineral Petrol 14(1):58-66 (in Chinese)

Liu XS (1983) Quaternary system of Sichuan basin. Sichuan Science and Technology Press, Chengdu (in Chinese)

Liu QF, Yu YY, Zhang XB (2015) Three-dimensional simulations of strong ground motion in the Shidian basin based upon the spectral-element method. Earthq Eng Eng Vib 14(3):385-398

Lu JQ, Li SY, Xie ZN et al (2012) Multi-channel analysis of surface wave method based determination of S-wave velocity structure of Chengdu Basin. J Earthq Eng Eng Vib 32(2):35-40 (in Chinese)

Ludwig WJ, Nafe JE, Drake CL (1970) Seismic refraction. The sea 4(Part 1):53-84

Meng LY, Shi BP (2011) Near-fault strong ground motion simulation of the May 12, 2008, Mw 7.9 Wenchuan earthquake by dynamical composite source model. Chin J Geophys 54(4):1010-1027 (in Chinese)

Nakamura T, Tsuboi S, Kaneda Y et al (2010) Rupture process of the 2008 Wenchuan, China earthquake inferred from teleseismic waveform inversion and forward modeling of broadband seismic waves. Tectonophysics 491(1):72-84

Olsen KB (2000) Site amplification in the Los Angeles basin from three-dimensional modeling of ground motion. Bull Seismol Soc Am 90(6B):S77-S94

Rong JS, Wang SY, Li XJ et al (2013) Calculation and analysis of seismic ground motion parameters for different engineering geological divisions of Chengdu plain. Acta Seismol Sin 35(4):543-552 (in Chinese)

Schmedes J, Archuleta RJ, Lavallée D (2010) Correlation of earthquake source parameters inferred from dynamic rupture simulations. J Geophys Res 115(B3):427-428

Somerville P, Irikura K, Graves R et al (1999) Characterizing crustal earthquake slip models for the prediction of strong ground motion. Seismol Res Lett 70(1):59-80

Song HB, Luo ZL (1995) The study of the basement and deep geological structures of Sichuan basin, China. Geosci Front 2(3-4):231-237 (in Chinese)

Stewart JP, Choi Y, Graves RW (2005) Empirical characterization of site conditions on strong ground motion. Pacific Earthquake Engineering Research Center, Berkeley

Wang YX, Mooney WD, Han GH et al (2005) Crustal P-wave velocity structure from Altyn Tagh to Longmen mountains along the Taiwan-Altay geoscience transect. Chin J Geophys 48(1):98-106 (in Chinese)

Wang WM, Zhao LF, Li J et al (2008) Rupture process of the Ms 8.0 Wenchuan earthquake of Sichuan, China. Chin J Geophys 51(5):1403-1410 (in Chinese)

Yuan YF (2008) Loss assessment of Wenchuan earthquake. J Earthq Eng Eng Vib 28(5):10-19 (in Chinese)

Zhang YG, Yang GZ (1983) Determination of Q-value by the coda wave for a portion of the Sichuan province. Acta Seismol Sin 5(3):304-312 (in Chinese)

Zhang W, Shen Y, Chen XF (2008) Numerical simulation of strong ground motion for the M s8. 0 Wenchuan earthquake of 12 May 2008. Sci China Ser D Earth Sci 51(12):1673-1682

Zhang Y, Feng WP, Xu LS et al (2009) Spatio-temporal rupture process of the 2008 great Wenchuan earthquake. Sci China Ser D Earth Sci 52(2):145-154

Zhao CP, Chen ZL, Zhou LQ et al (2009) Rupture process of the 8.0 Wenchuan earthquake of Sichuan, China: the segmentation feature. Chin Sci Bull 54(22):3475-3482 (in Chinese)

Zhao CP, Chen ZL, Hua W et al (2011) Study on source parameters of small to moderate earthquakes in the main seismic active regions, China mainland. Chin J Geophys 54(6):1478-1489 (in Chinese) 